Data Article

\title{
SEM, EBSD, laser confocal microscopy and FE-SEM data from modern Glycymeris shell layers
}

\author{
Gaia Crippa ${ }^{\mathrm{a}, *}$, Erika Griesshaber ${ }^{\mathrm{b}}$, Antonio G. Checa ${ }^{\mathrm{c}}$, \\ Elizabeth M. Harper ${ }^{d}$, Maria Simonet Roda ${ }^{b}$, \\ Wolfgang W. Schmahl ${ }^{\mathrm{b}}$ \\ a Università degli Studi di Milano, Dipartimento di Scienze della Terra 'A. Desio', via Mangiagalli 34, Milano 20133, \\ Italy \\ ${ }^{\mathrm{b}}$ Department für Geo- und Umweltwissenschaften, Ludwig-Maximilians Universität München, Munich, Germany \\ ' Departamento de Estratigrafía y Paleontología, Universidad de Granada, Instituto Andaluz de Ciencias de la Tierra, \\ CSIC-Universidad de Granada, Armilla, Granada 18100, Spain \\ ${ }^{\mathrm{d}}$ Department of Earth Sciences, University of Cambridge, Cambridge CB2 3EQ United Kingdom
}

\section{A R T I C L E I N F O}

\section{Article history:}

Received 22 October 2020

Revised 10 November 2020

Accepted 13 November 2020

Available online 19 November 2020

\section{Keywords:}

Bivalve

Aragonite

Crossed-lamellae

Myostracum

Shell textures

Shell microstructures

\begin{abstract}
A B S T R A C T
Here, we provide the dataset associated with the research article "Orientation patterns of aragonitic crossed-lamellar, fibrous prismatic and myostracal microstructures of modern Glycymeris shells" [1]. Based on several tools (SEM, EBSD, laser confocal microscopy and FE-SEM) we present original data relative to the microstructure and texture of aragonite crystallites in all Glycymeris shell layers (crossed-lamellar, complex crossed-lamellar, fibrous prismatic and pedal retractor and adductor myostraca) and address texture characteristics at the transition from one layer to the other, identifying similarities and differences among the different layers. Shells were cut transversely, obliquely and longitudinally in order to obtain different orientated sections of the outer and inner layer and of the myostraca. The identification of major microstructural elements was provided by detailed SEM and laser confocal microscopy images. Microstructure and texture characterization was based on EBSD measurements
\end{abstract}

DOI of original article: 10.1016/j.jsb.2020.107653

* Corresponding author.

E-mail address: gaia.crippa@unimi.it (G. Crippa). 
presented as band contrast images and as color-coded crystal orientation maps with corresponding pole figures. Crystal co-orientation was measured with the MUD value. Finally, the distribution of the organic matrix occluded within the outer crossed-lamellar layer was revealed using FE-SEM. These data, besides providing a modern unaltered Glycymeris reference to detect diagenetic alteration in fossil analogs used for paleoenvironmental reconstructions, are useful to better comprehend the mechanisms of bivalve shell formation.

(c) 2020 The Authors. Published by Elsevier Inc.

This is an open access article under the CC BY-NC-ND license (http://creativecommons.org/licenses/by-nc-nd/4.0/)

\section{Specifications Table}

\author{
Subject \\ Specific subject area \\ Type of data \\ How data were acquired
}

Data format

Parameters for data

collection

Description of data collection

Data source location

Data accessibility

Related research article

\author{
Structural biology \\ Modern bivalve shell microstructures and textures \\ SEM, EBSD, FE-SEM and laser confocal microscopy images \\ SEM: Cambridge S-360 scanning electron microscope with lanthanum \\ hexaboride $\left(\mathrm{LaB}_{6}\right)$ source and operating at an acceleration voltage of \\ $20 \mathrm{kV}$; \\ EBSD: Hitachi SU5000 field emission SEM, equipped with an Oxford \\ EBSD detector; \\ Laser confocal microscopy: Keyence 3D laser scanning confocal \\ microscope (VK-X1000 series); \\ FE-SEM: Hitachi S5000 field emission SEM. \\ Raw, Analyzed \\ Modern shells were cut along three orientations and embedded in \\ epoxy resin. Then shell sections were: 1) ground smooth using SiC \\ powder, etched with $5 \% \mathrm{HCl}$ for $15 \mathrm{~s}$, washed in demineralized water, \\ dried and gold coated for SEM; 2) subjected to sequential mechanical \\ grinding and polishing steps and carbon coated for EBSD; 3 ) \\ decalcified and etched for FE-SEM. \\ Visualization of major structural elements composing the different \\ shell layers was imaged with SEM and laser confocal microscopy. \\ Microstructure and texture characterization is based on EBSD. \\ Information from EBSD measurements is presented as band contrast \\ images and as color-coded crystal orientation maps with \\ corresponding pole figures. Co-orientation statistics are derived from \\ pole figures and given by MUD values. The distribution of the organic \\ matrix within the shells was imaged using FE-SEM. \\ Glycymeris nummaria: Misano Adriatico in northern Italy \\ $\left(43^{\circ} 58^{\prime} 48.3^{\prime \prime} \mathrm{N} ; 12^{\circ} 42^{\prime} 12.6^{\prime \prime} \mathrm{E}\right)$; \\ Glycymeris glycymeris: Baie de la Fresnaye, near the towns of Fréhel \\ and Pléboulle in Brittany, France $\left(48^{\circ} 37^{\prime} 17.7^{\prime \prime} \mathrm{N} ; 2^{\circ} 19^{\prime} 50.3^{\prime \prime} \mathrm{W}\right)$. \\ Data is with this article \\ Crippa, G., Griesshaber, E., Checa, A., Harper, E., Simonet Roda, M., \\ Schmahl, W.W., 2020. Orientation patterns of aragonitic \\ crossed-lamellar, fibrous prismatic and myostracal microstructures of \\ modern Glycymeris shells, J. Struct. Biol. 212, 107653. \\ https://doi.org/10.1016/j.jsb.2020.107653
}

\section{Value of the Data}

- These data provide a full characterization of the microstructures and textures of the different shell layers composing modern Glycymeris shells based on a multi-methodological approach (SEM, EBSD, laser confocal microscopy and FE-SEM). This allows to obtain a modern unaltered reference for fossil Glycymeris shells to be used in detecting diagenetic alteration in fossil analogs. 
- The data presented here are valuable to researchers investigating mollusc shell mechanism formation.

- These data may be used by other researchers to better understand shell biomineralization processes or to develop biologically inspired materials.

- The combination of microstructure imaging with microstructure/texture measurements is a robust evaluation approach to assess the degree of overprint in fossil material, which can be applied to other invertebrate taxa used for paleoenvironmental reconstructions.

\section{Data Description}

The shells of the bivalves Glycymeris glycymeris (Linnaeus, 1758) and Glycymeris nummaria (Linnaeus, 1758) are abundant in modern and past marine environments and are widely used for environmental studies [2-5]. A better understanding of modern pristine Glycymeris shell microstructures and textures is fundamental in providing a reference for the detection of diagenetic overprint in fossil Glycymeris analogs used for paleoenvironmental reconstructions [6, 7]. Here, we focus on mineral unit size, morphology and orientation of crystallites in the shell layers (crossed-lamellar, complex-crossed lamellar, fibrous prismatic) and in the adductor and pedal retractor myostraca of G. glycymeris and G. nummaria. Also, we analyze the mode of aragonite orientation at the transition from one microstructure to the other. Glycymeris shells were sectioned along three different orientations: transversally, obliquely and longitudinally (Figs. 1-2). Figs. 3 to 5 show the microstructure of the different shell layers based on SEM images with a focus on the transition between the myostraca and the other shell layers. SEM high resolution images in TIFF are provided in the Supplementary Material (Figs. S3S5). EBSD band contrast images and density distributions of $a-$, b- and c-axes poles for the

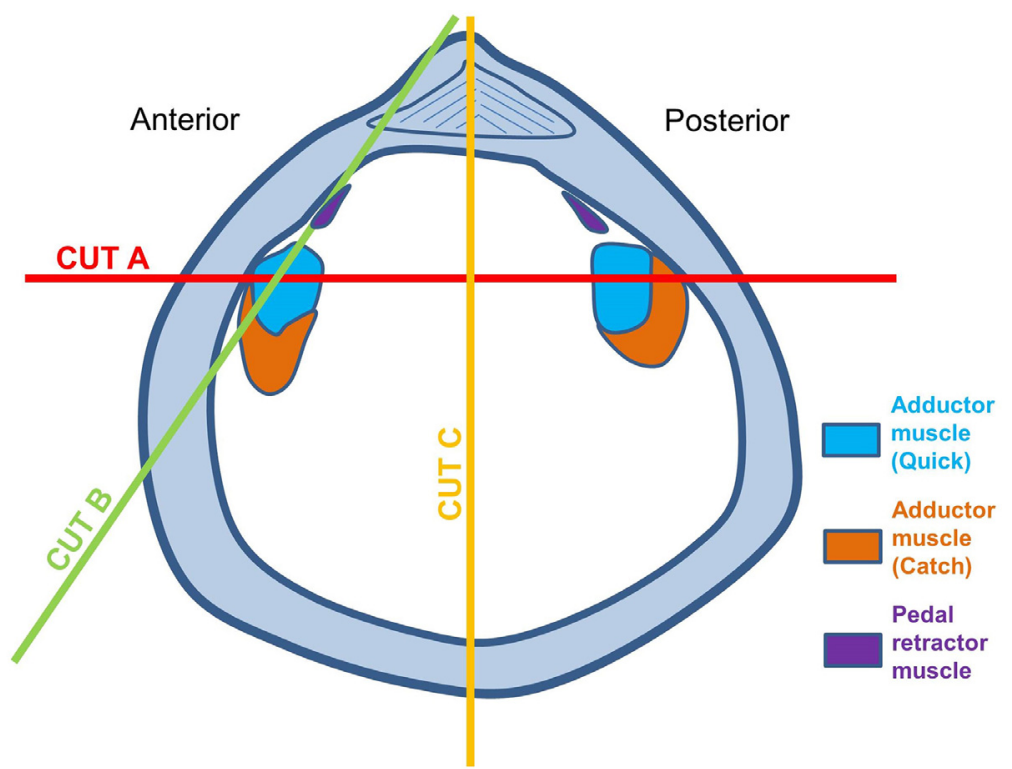

Fig. 1. Schematic image of a right valve of Glycymeris (modified from [8]), showing how specimens were sectioned for the analyses presented here. Shells were cut along three preferential orientations: i) transversely (cut A), in order to cut both adductor myostraca [MPUM 11860 (Gla, GIb; Glycymeris nummaria)]; ii) obliquely (cut B), in order to cut one adductor and the pedal retractor myostraca [MPUM 11861 (GG1; Glycymeris glycymeris)]; iii) longitudinally (cut C), along the axis of maximum growth, i.e. the axis perpendicular to the growth lines [MPUM 11202 (AG1, AG2; Glycymeris glycymeris)]. 


\section{CUT A}

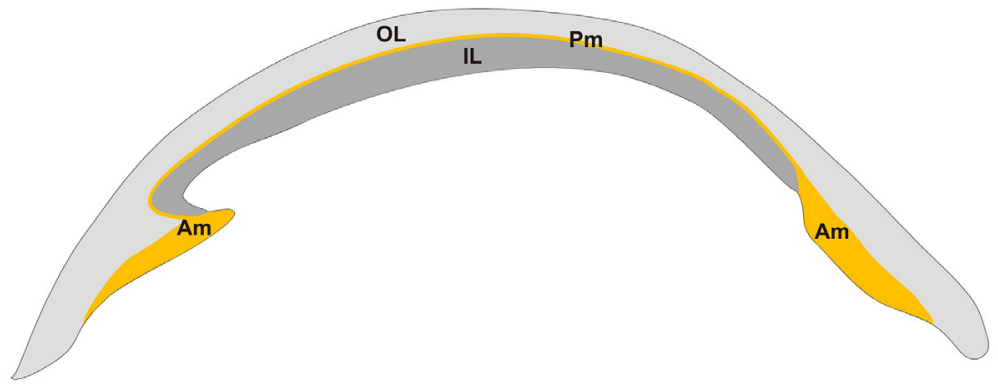

\section{CUT B}

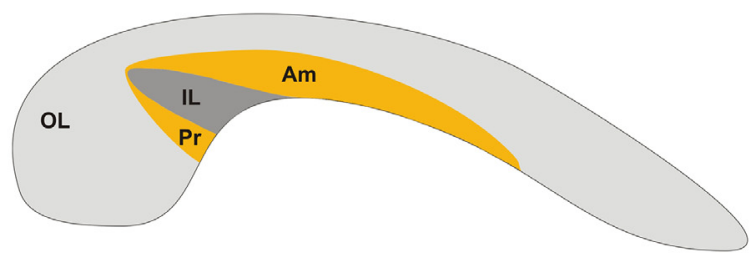

\section{CUT C}

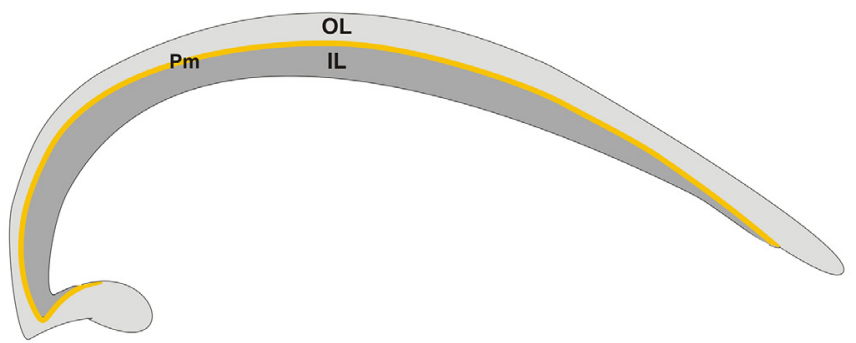

Fig. 2. Shell sections of G. glycymeris and G. nummaria, cut along the three orientations described in Fig. 1: transversely (cut A), obliquely (cut B), longitudinally (cut C). Am: adductor myostracum; IL: inner layer; OL: outer layer; Pm: pallial myostracum; Pr: pedal retractor myostracum.

crossed-lamellar, complex-crossed lamellar and fibrous prismatic layer are presented in Figs. 6 and 7. EBSD measurements shown in Fig. 8 depict aragonite orientations in the adductor myostracum, while Figs. 9 and 10 visualize the presence of a twin relationship within the first-order lamellae of the outer layer that is fully transmitted to the aragonite crystallites of the adjacent pedal retractor myostracum. Mineral unit and prism organization in the adductor myostracum and the transition from crossed-lamellar to myostracal aragonite are depicted in Fig. 11.

Laser confocal microscopy and SEM images identify a connection between the pedal retractor and the adductor myostracum in the hinge plate of both Glycymeris species, as shown in Fig. 12 and Fig. 3B, respectively.

The outer crossed-lamellar shell layer and the biopolymer matrix that is occluded within it have been characterized with FE-SEM images (Figs. 13-14). 

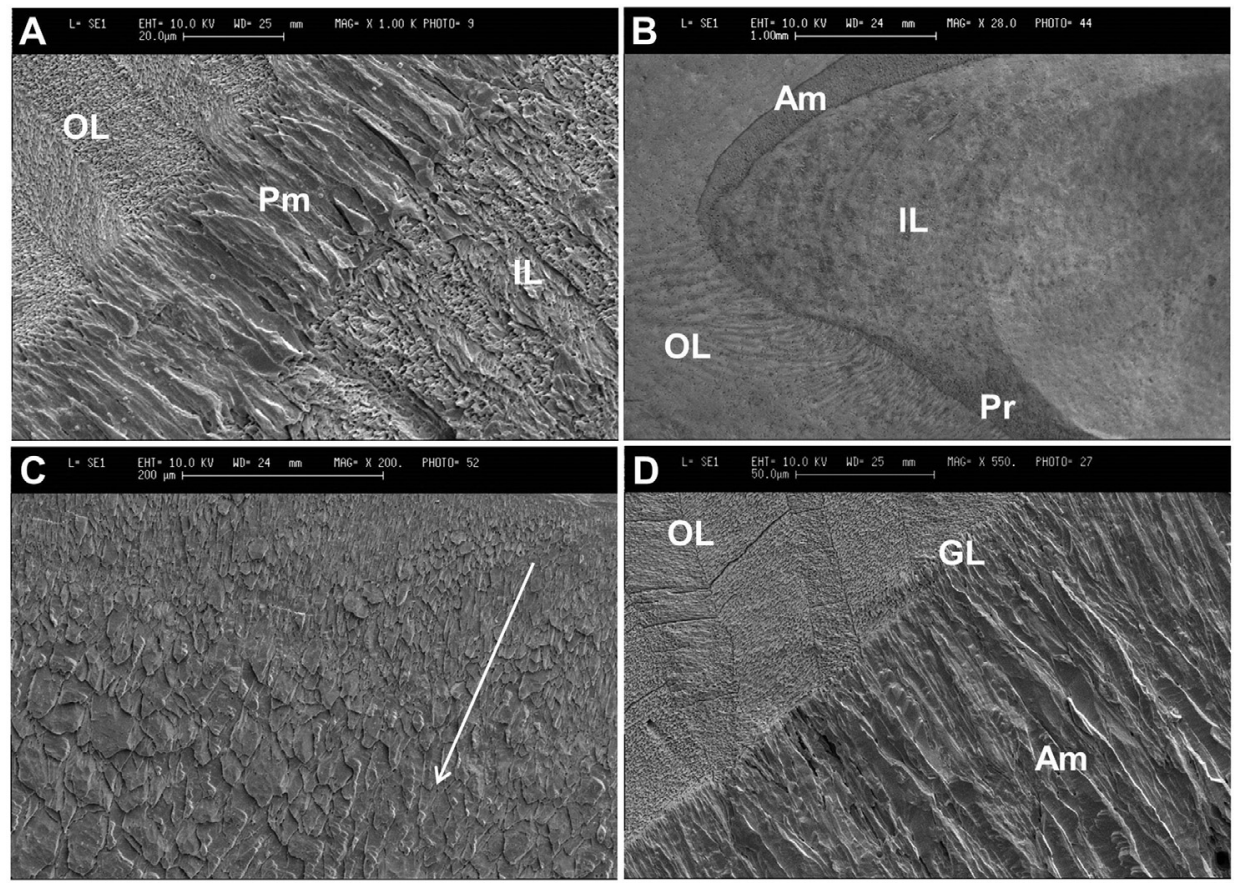

Fig. 3. Scanning electron microscope images showing the microstructure of Glycymeris shells. Am: adductor myostracum; GL: growth lines; IL: inner layer; OL: outer layer; Pm: pallial myostracum; Pr: pedal myostracum.

A) Outer and inner shell layers divided by the pallial myostracum [MPUM 11860 (Gla, Glycymeris nummaria)]; B) connection between the adductor myostracum and the pedal retractor myostracum in the hinge plate [MPUM 11861 (GG1, Glycymeris glycymeris)]; C) myostracal prisms increasing in size towards the inner part of the valve [MPUM 11861 (GG1, Glycymeris glycymeris)]; D) prisms of the adductor myostracum becoming thinner in correspondence with the digitations, which represent growth episodes [MPUM 11860 (GIb, Glycymeris nummaria)].

Finally, MUD values are calculated for comparison between the fibrous prismatic layer and the adductor myostracum (Fig. 15); a steady increase in aragonite co-orientation strength towards innermost myostracal surfaces is observed. The increase in crystal size and in crystal coorientation strength indicates the formation of myostracal layers by competitive growth, as it has been observed also in the columnar layer of brachiopod shells and in cephalopod spherulitic shells (Fig. 16).

\section{Experimental Design, Materials and Methods}

\subsection{Sample collection and mode of sectioning}

Modern shells here analyzed belong to two Glycymeris species: Glycymeris nummaria collected at Misano Adriatico in northern Italy and Glycymeris glycymeris, collected at Baie de la Fresnaye, near the towns of Fréhel and Pléboulle in Brittany, France. The investigated material is housed in the Dipartimento di Scienze della Terra "A. Desio", Università di Milano and is registered with reference numbers consisting of a prefix MPUM followed by a five-digit number.

Shells of both species were cut along three preferential orientations using a low speed saw with a thin diamond blade (Figs. 1, 2): i) transversely (cut A), in order to cut both adductor myostraca [MPUM 11860; Glycymeris nummaria]; ii) obliquely (cut B), in order to cut one adductor and the pedal retractor myostraca [MPUM 11861; Glycymeris glycymeris]; iii) 


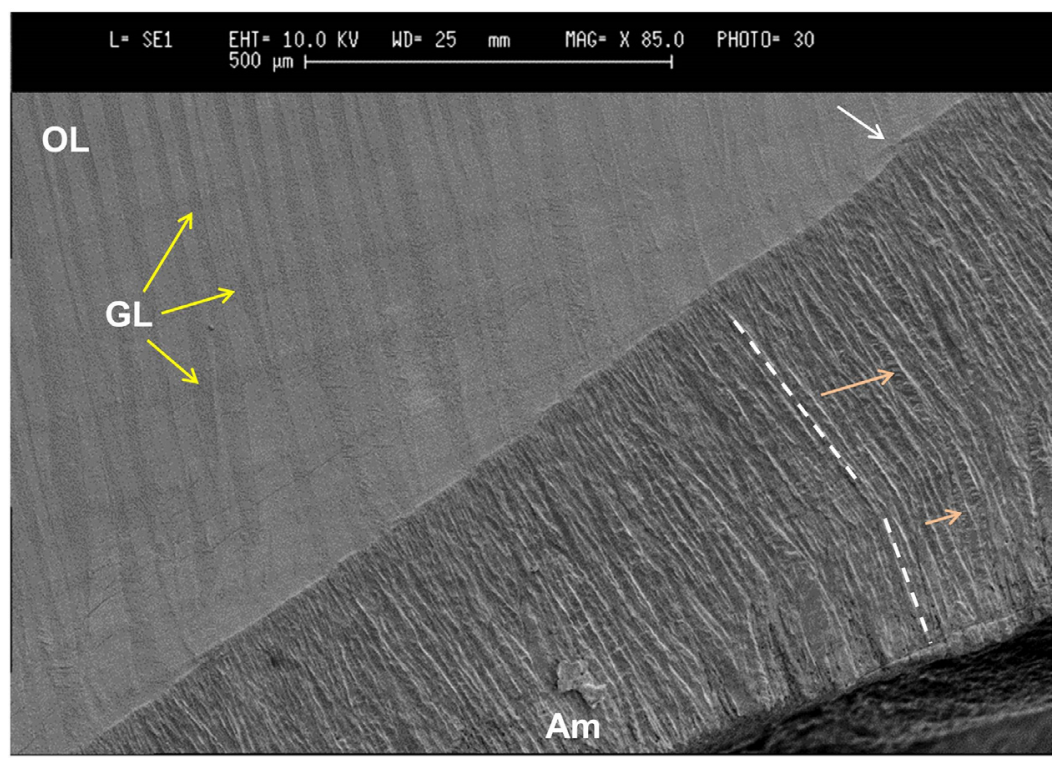

Fig. 4. Scanning electron microscope image showing the microstructure of Glycymeris shells. Am: adductor myostracum; GL: growth lines; OL: outer layer. Prisms of the adductor myostracum becoming thinner in correspondence with the digitations (white arrow), then passing into growth lines (yellow arrows). Also, two different orientations within the adductor myostracum are observable (dashed lines). They correspond to the changing tracing of the growth lines (orange arrows) [MPUM 11860 (GIb, Glycymeris nummaria)].

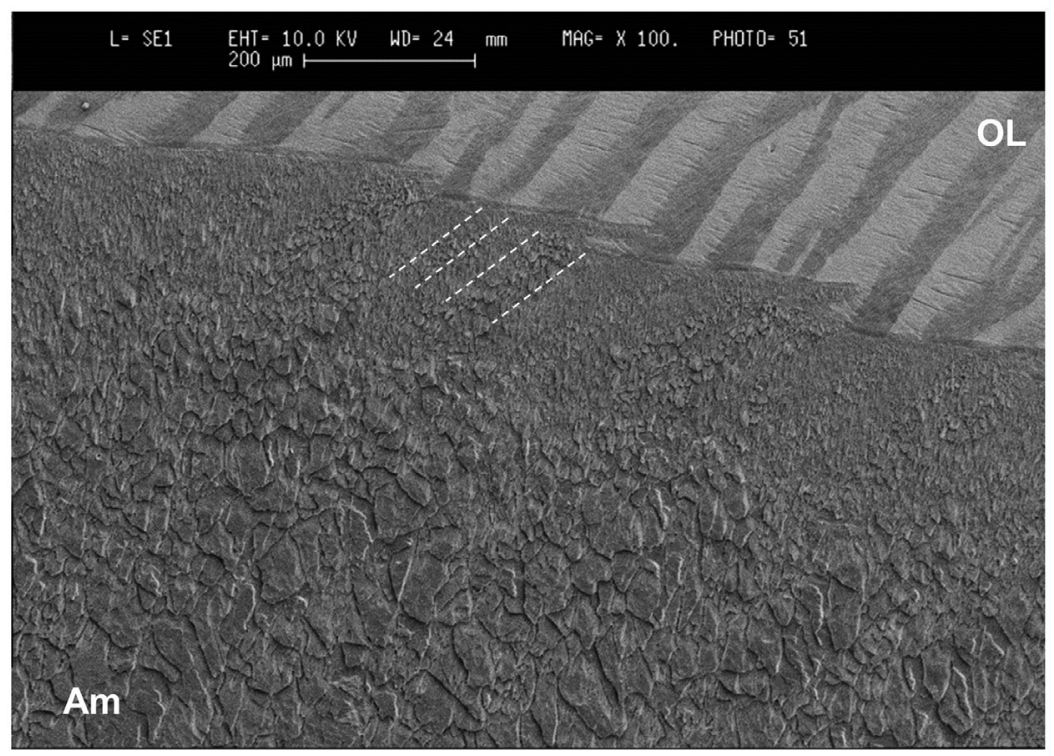

Fig. 5. Scanning electron microscope image showing the microstructure of Glycymeris shells. Am: adductor myostracum; OL: outer layer. Prisms of the adductor myostracum becoming thinner in correspondence with the digitations, which represent growth episodes. The orientation of first-order lamellae is transferred to the first part of the adductor myostracum (white dashed lines) [MPUM 11861 (GG1, Glycymeris glycymeris)]. 


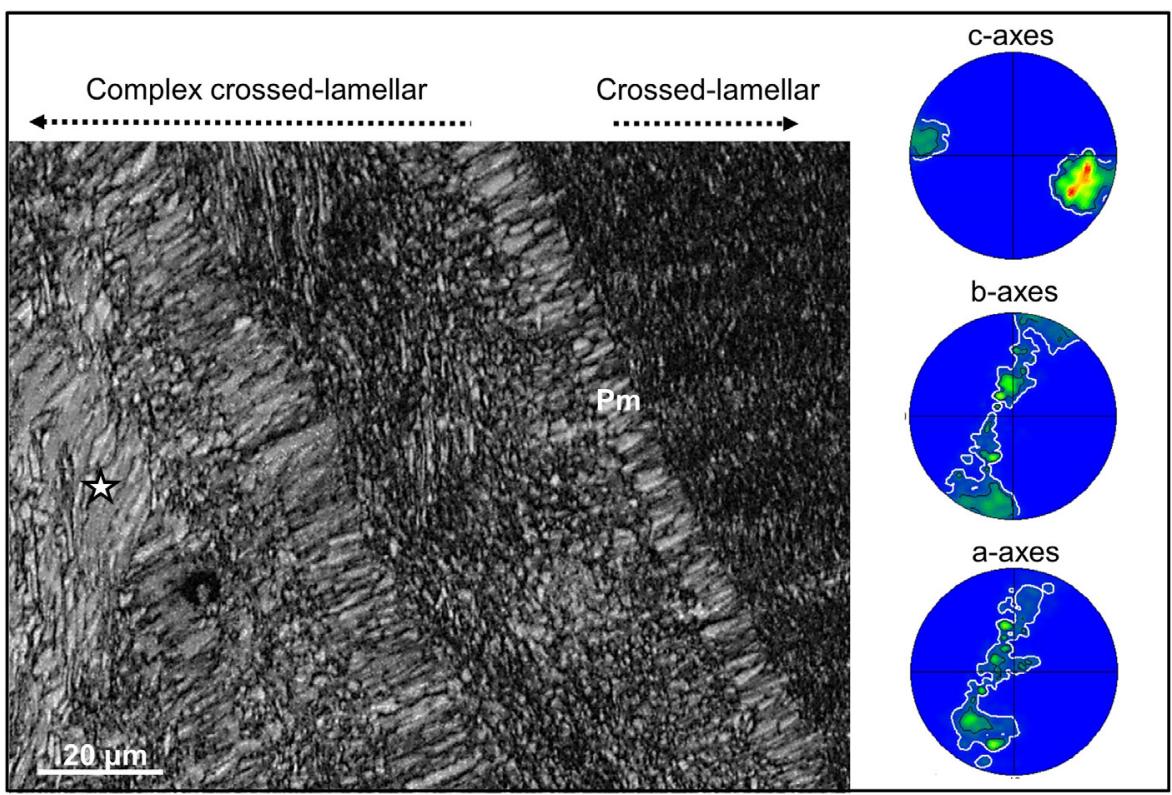

Fig. 6. EBSD band contrast image and pole figure in a transversely cut shell [Cut A; MPUM 11860 (Gla, Glycymeris nummaria)] depicting microstructural characteristics at the transition from complex crossed-lamellar to crossed-lamellar layers (see also Fig. 5 in Crippa et al. [1]). The white star indicates a block of second-order lamellae. Pm: pallial myostracum.

longitudinally (cut C), along the axis of maximum growth, i.e. the axis perpendicular to the growth lines [MPUM 11202; Glycymeris glycymeris].

\subsection{Scanning electron microscope}

Shell sections of both G. glycymeris and G. nummaria were imaged with SEM in order to visualize major structural elements that compose the different shell layers (Figs. 3-5; Figs. S3-S5 in the Supplementary Material). Sample preparation followed the procedure proposed by Crippa et al. [9] for brachiopod shells, with few modifications (i.e. higher exposure time to hydrochloric acid). Each valve was cut (Cut A, B and C described in paragraph 2.1) using a low speed diamond saw and each section was embedded in a transparent bicomponent epoxy resin (Araldite DFB + hardener HY956, in proportion 10:1 or 8:2) forming small blocks. Every block was ground smooth manually or mechanically using Silicon Carbide $(\mathrm{SiC})$ powder of two different granulometries (400 and 1000) and carefully washed with water to remove SiC remains. Sections were then etched with $5 \%$ hydrochloric acid $(\mathrm{HCl})$ for $15 \mathrm{~s}$ in order to reveal the details of the microstructure and then immediately rinsed with abundant demineralized water to stop the effect of the acid. After the treatment with $\mathrm{HCl}$, the sections were carefully dried with compressed air, paying attention to not damage the microstructure emphasized by the acid. Finally, each block was coated with gold and observed at the SEM Cambridge S-360 with lanthanum hexaboride $\left(\mathrm{LaB}_{6}\right)$ cathodes.

\subsection{Electron backscattered diffraction}

The analysis of microstructure and texture characterization is based on Electron Backscatter Diffraction (EBSD) measurements. Shell sections of G. glycymeris and G. nummaria (Cut A 

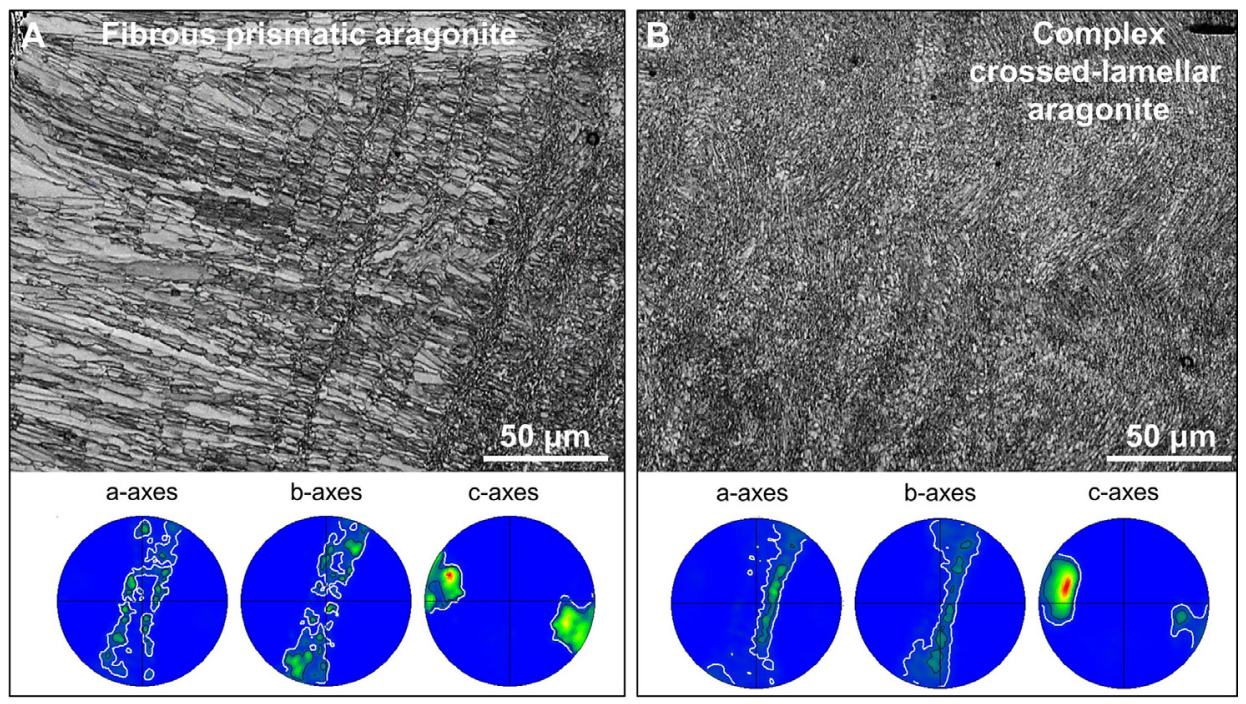

Fig. 7. EBSD band contrast images and density distributions of a-, b- and c-axes poles in a transversely cut shell [Cut A; MPUM 11860 (Gla, Glycymeris nummaria)] highlighting the microstructure and texture of aragonite in the fibrous prismatic and the adjacent complex crossed-lamellar layers (see also Figs. 6, 7 in Crippa et al. [1]).
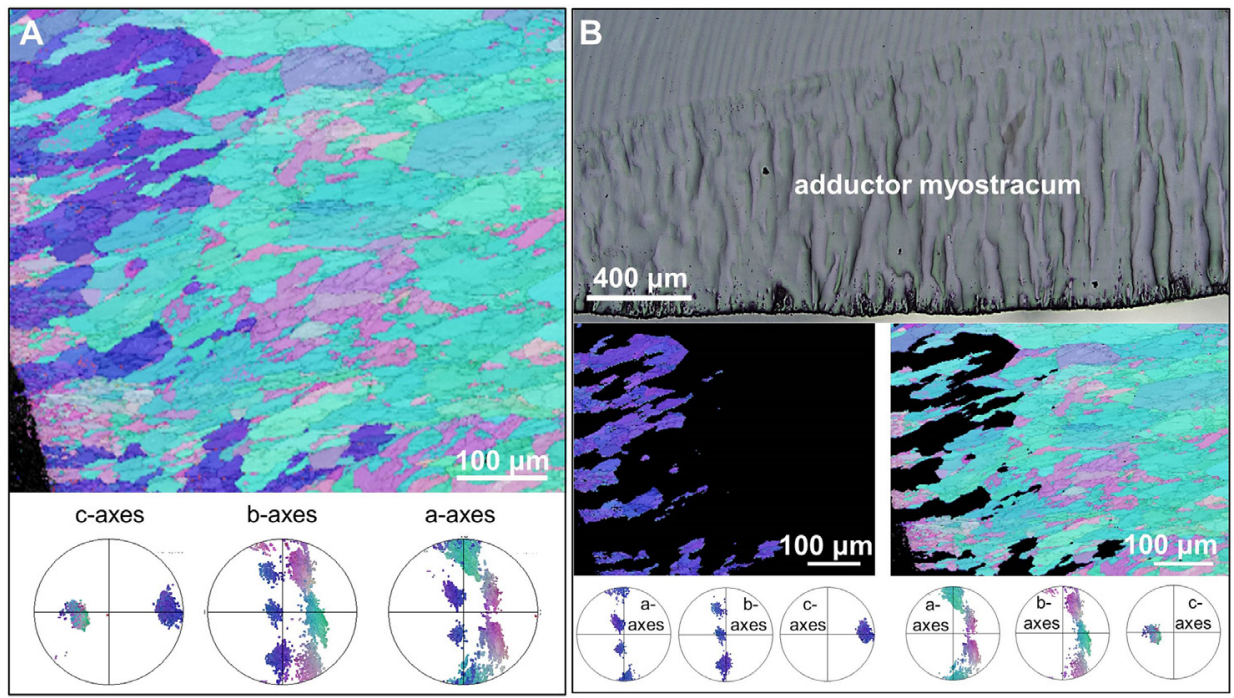

Fig. 8. EBSD measurement depicting aragonite orientations in the adductor myostracum. The shell is sectioned transversely [Cut A; MPUM 11860 (Gla, Glycymeris nummaria)]. Three main orientations (dark blue, light blue, pink) are visible differing from each other in all three aragonite axes. In B subsets of the measurement given in A are shown.

and B, see paragraph 2.1) were embedded in an epoxy resin (EpoFix, Struers Inc.), subjected to several sequential mechanical grinding and polishing steps; the final step consists in an etchpolishing with colloidal alumina in a vibratory polisher (Buehler Vibro Med 2). Subsequently, the samples were ion milled in an ion milling system (Hitachi IM 4000+). For EBSD analysis the shell section surfaces were coated with $4-6 \mathrm{~nm}$ of carbon. EBSD measurements were performed 

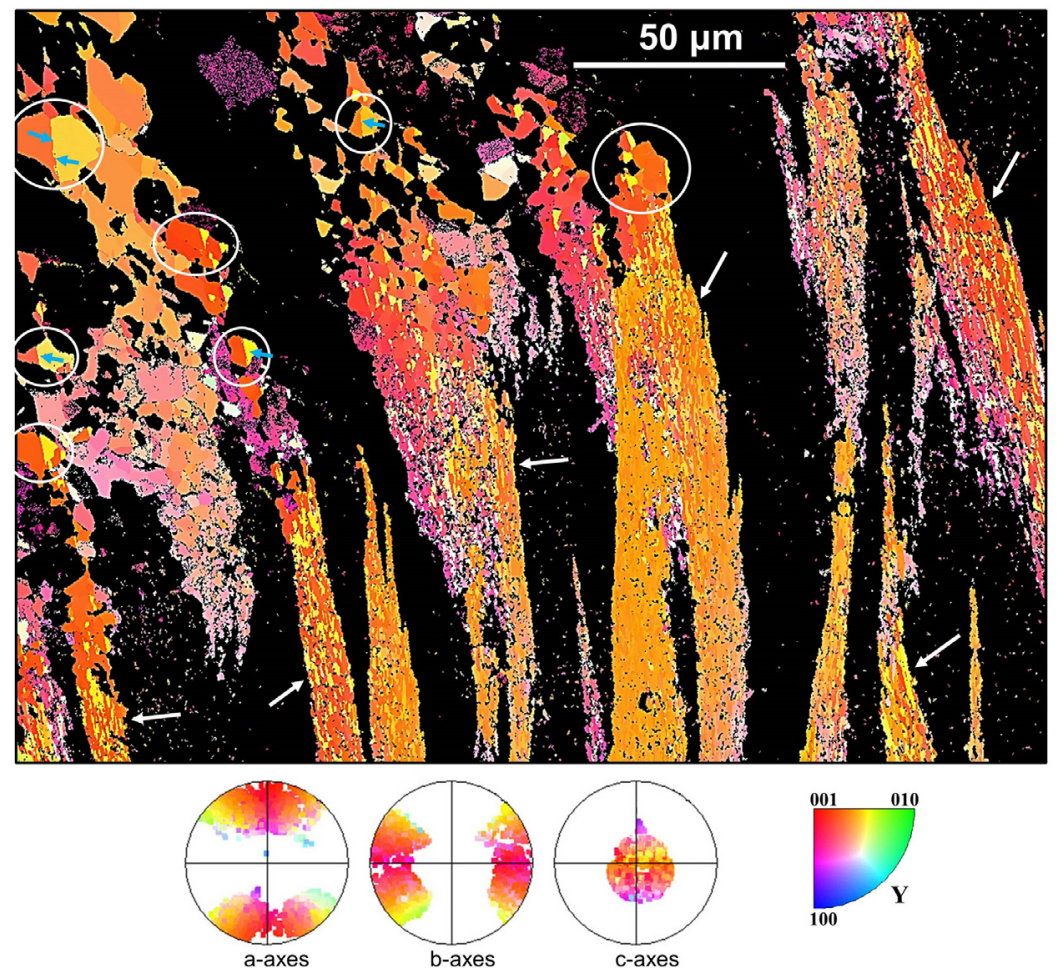

Fig. 9. EBSD measurement showing aragonite orientation in one set of alternating first-order lamellae and within the adjacent pedal retractor myostracum in an obliquely cut shell [Cut B, MPUM 11861 (GG1; Glycymeris glycymeris)]. The color-code used for orientation is given in the figure. The yellow and red colors within the first-order lamellae (white arrows) visualize the presence of a twin relationship. Orientation as well as twinning characteristics are fully transmitted to the aragonite of the adjacent pedal retractor myostracum. Some individual twinned crystals are encircled in white. The twinning plane, separating the two crystals of a twin (orange and yellow crystals) is also visible (blue arrows).

using a Hitachi SU5000 field emission SEM, equipped with an Oxford EBSD detector. The SEM was operated at $20 \mathrm{kV}$ and measurements were evaluated with the CHANNEL 5 HKL software. EBSD data are shown as band contrast measurement images and as color-coded crystal orientation maps with corresponding pole figures (Figs. 6-11), with the latter giving either individual data points or, in the contoured version, the strength of the clustering of poles. When contouring, we use the lowest possible degree for half width and cluster size, a half width of five and a cluster size of three degrees, respectively. The half width controls the extent of the spread of the poles over the surface of the project sphere. A cluster comprises data with the same orientation.

EBSD band contrast gives the signal strength of the EBSD-Kikuchi diffraction pattern and is displayed as a gray-scale component in a map. Accordingly, the strength of the diffraction signal is high when a mineral is detected (bright in the map), whereas it is weak or absent when a polymer, such as organic matrix, is scanned (dark/black in the map).

Co-orientation statistics are derived from pole figures and are given by the MUD (multiple of uniform (random) distribution) values, which measures texture sharpness in the scanned area; a high MUD value indicates high crystal co-orientation, while a low MUD value reflects a low co-orientation, i.e. high misorientation (Figs. 15-16). 


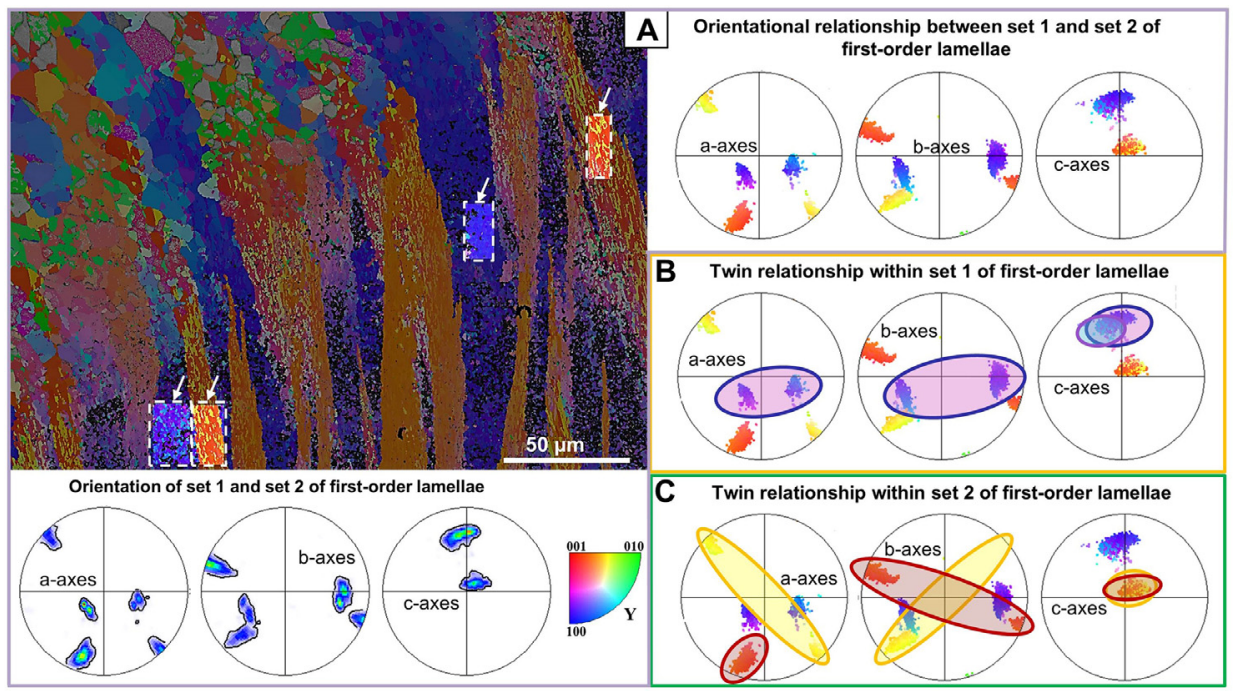

Fig. 10. Subsets (highlighted by a dashed white rectangle and indicated by white arrows) of an EBSD scan taken on an oblique cut [Cut B, MPUM 11861 (GG1; Glycymeris glycymeris)] through crossed-lamellar and pedal myostracal layers (see also Figs. 15, 16 in Crippa et al. [1]). The used color-code is given in A. The pole figures show: A) the orientation pattern between the two sets of first-order lamellae (set 1: light to dark blue; set 2: yellow and red) and B, C) orientation pattern and twin relationship within either set 1 or set 2 of first-order lamellae.
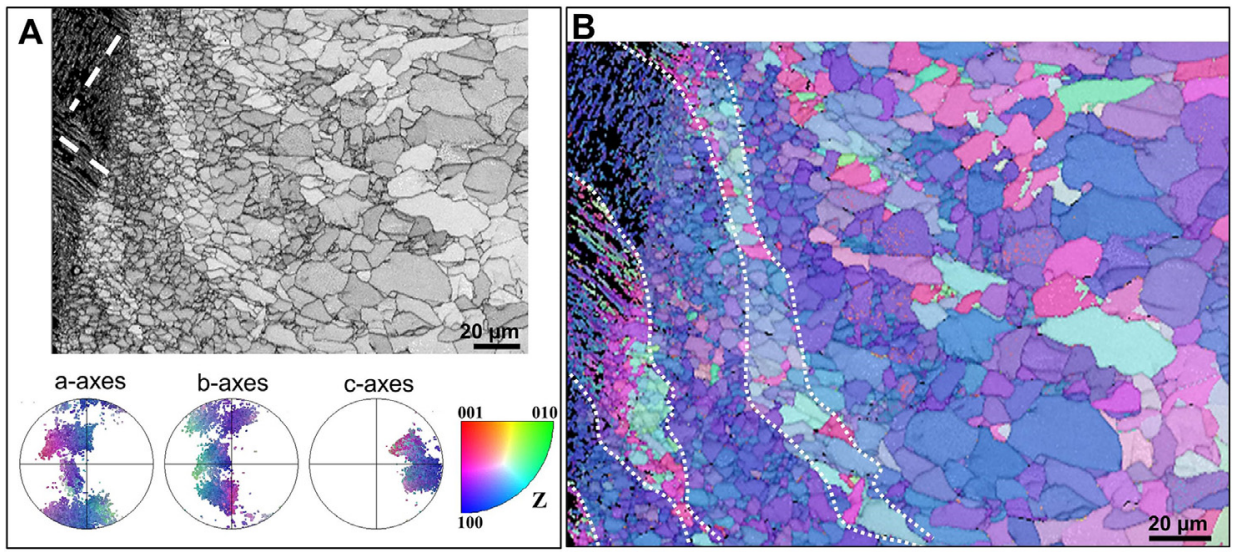

Fig. 11. EBSD band contrast (A) and orientation (B) measurement images of an obliquely cut shell [Cut B, MPUM 11861 (GG1; Glycymeris glycymeris)] depicting mineral unit and prism organization in adductor myostracal shell portions and the transition from crossed-lamellar to myostracal aragonite. The following features are visible: i) the sequence of second-order lamellae (dashed lines in A) within the two sets of first-order lamellae; ii) the transfer of aragonite orientation from the crossed-lamellar shell to the adjacent myostracum; iii) the preservation of crystal morphologies and hierarchical organization of the hard materials; iv) the increase in crystallite size towards inner myostracal surfaces. This figure gives the full measurement of the two subsets presented in Fig. 17 in Crippa et al. [1].

\subsection{Laser confocal microscopy}

Overview images for visualization of the different shell layers and of the myostracum were taken with a Keyence 3D laser scanning confocal microscope (VK-X1000 series) (Fig. 12). Shell 


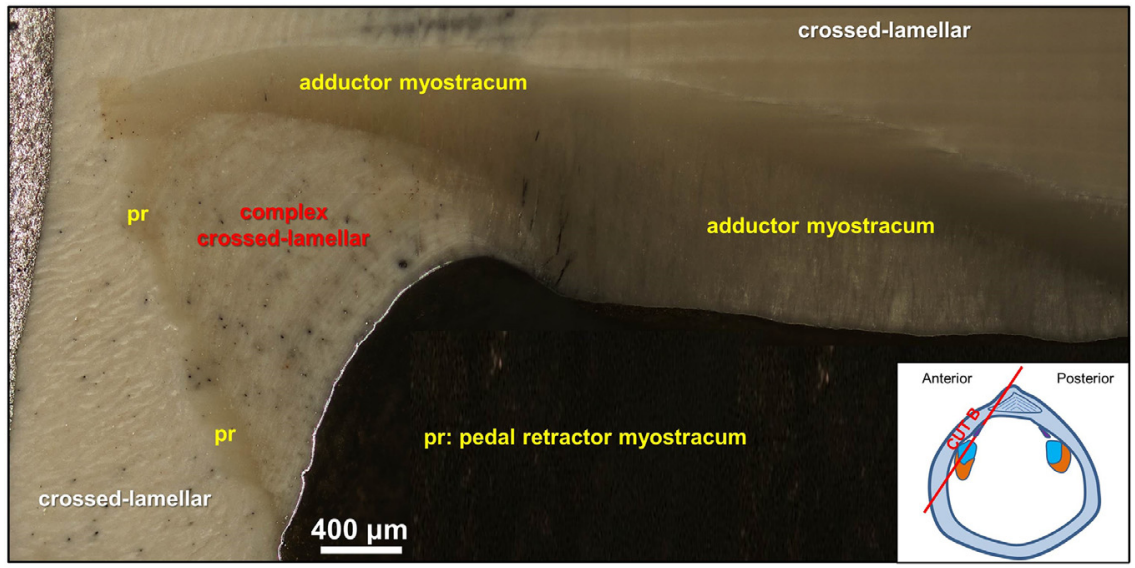

Fig. 12. Laser scanning confocal microscope image showing the spatial arrangement between outer crossed-lamellar, inner complex crossed-lamellar, adductor and pedal myostracal shell layers in an obliquely cut shell [Cut B, MPUM 11861 (GG1; Glycymeris glycymeris)]. We observe clearly that the two myostraca are interconnected.

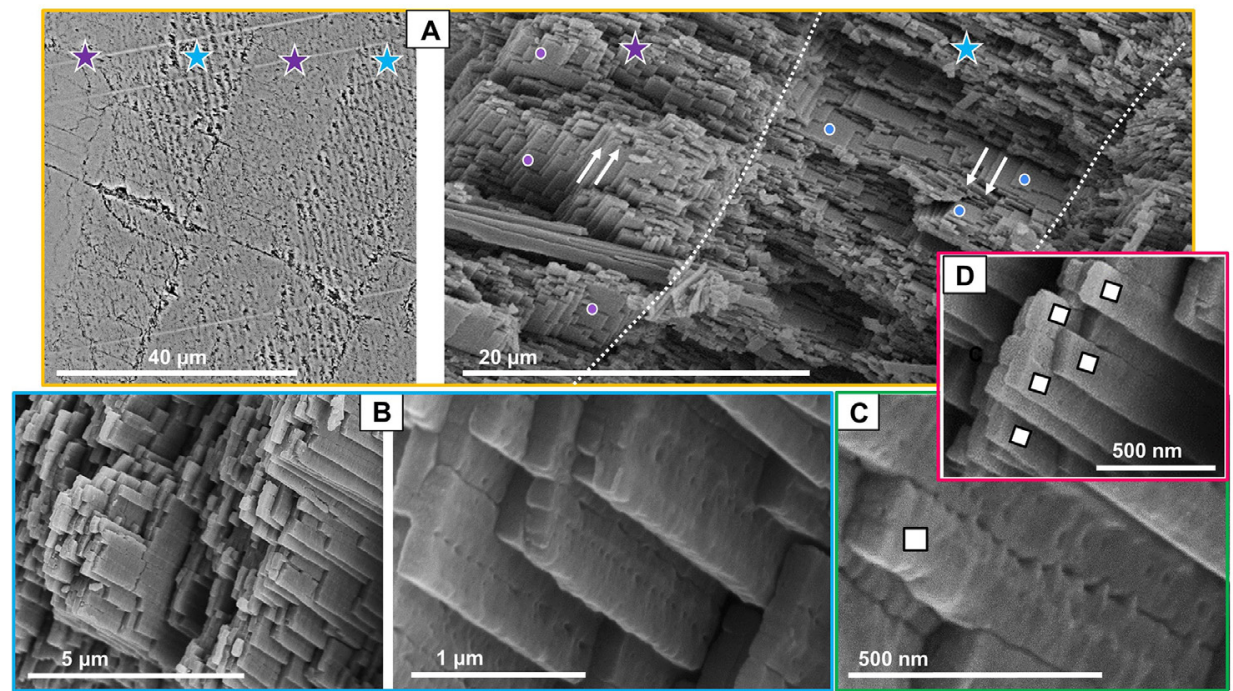

Fig. 13. FE-SEM images of first-, second- and third-order lamellae. A) The two sets of first-order lamellae are marked with blue and magenta stars; white arrows indicate the mode of orientation and tilt of second-order lamellae within adjacent first-order lamellae. B) Arrays of second-order lamellae within first-order lamellae. C, D) Third-order lamellae (white rectangles in $\mathrm{C}$ and $\mathrm{D}$ ) and their specific mode of interlinkage (C).

sections were embedded in epoxy resin and were polished with many sequential polishing steps for preparation of highly even sample surfaces. The samples were not coated.

\subsection{FE-SEM imaging}

Pieces of Glycymeris shells $(3 \times 3 \mathrm{~mm})$ were cut out at defined regions from a cross-section through the shell, were decalcified and etched for visualizing the distribution of the organic matrix within the shells (Figs. 13-14). Subsequent to attachment onto a metal holder, even surfaces 


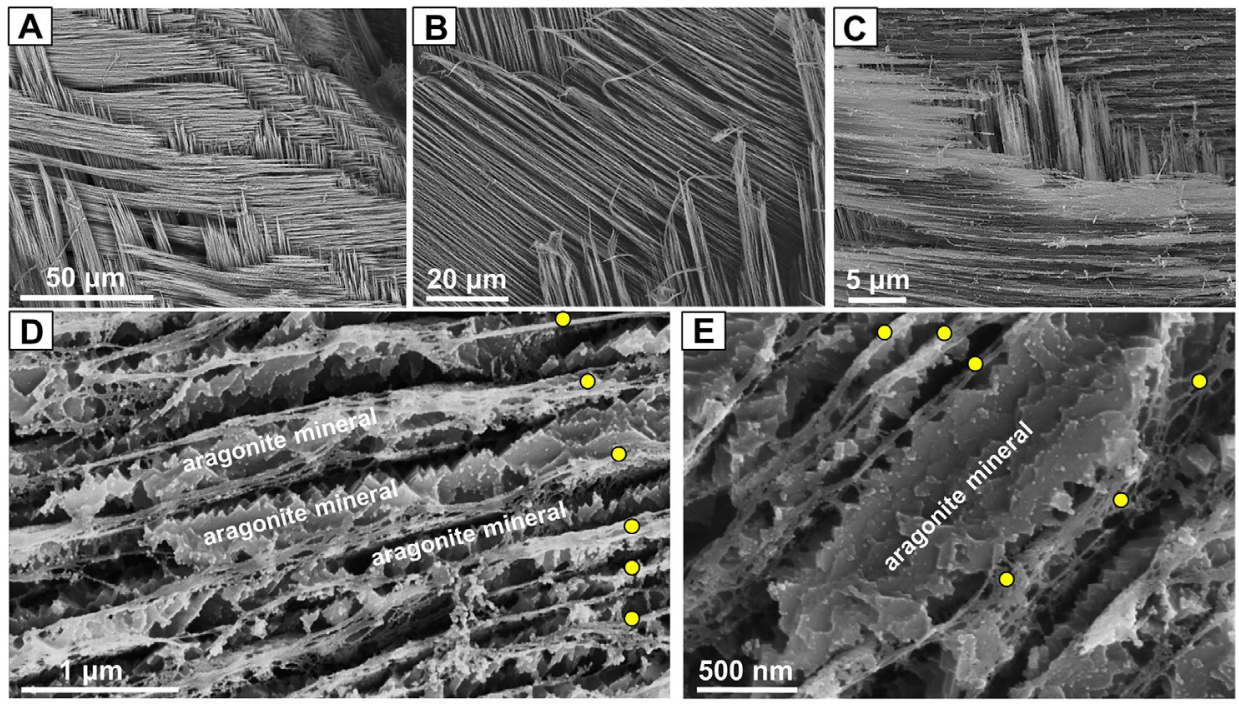

Fig. 14. FE-SEM images showing interleaved fabric of the biopolymer matrix that is occluded within the crossed-lamellar shell (A, B, C) and aragonite laths embedded in the extracellular matrix (yellow circles in D, E).
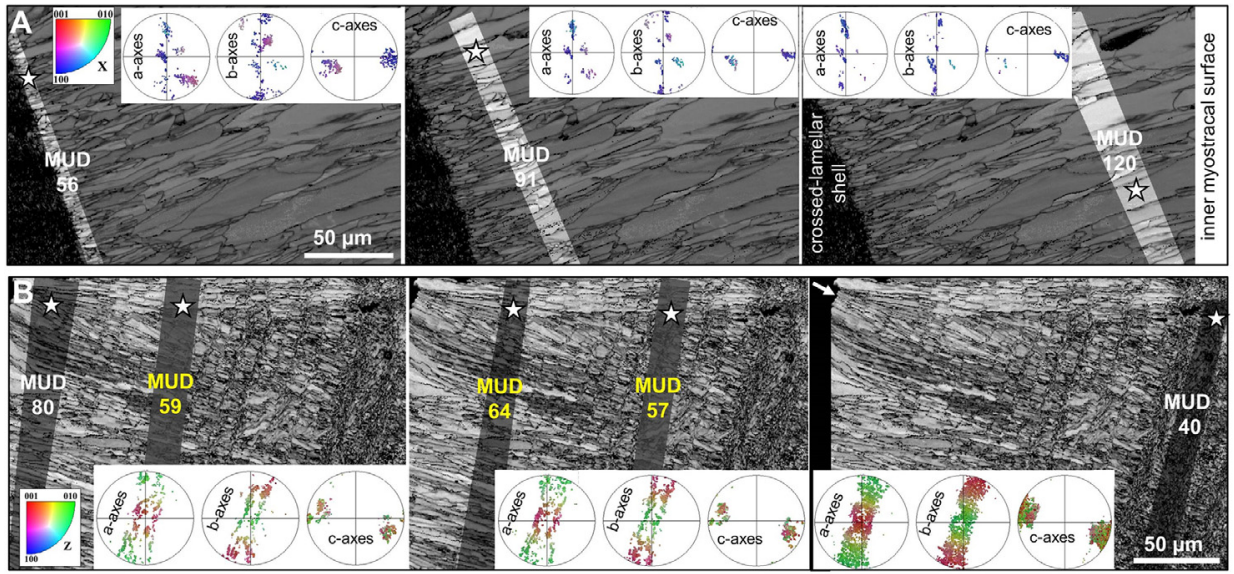

Fig. 15. Change in aragonite co-orientation strength in different parts of the adductor myostracum (A) and the fibrous prismatic shell layer (B). The shell is sectioned transversely [Cut A; MPUM 11860 (Gla, Glycymeris nummaria)]. MUD values were calculated for those regions that are highlighted in the band contrast image and are marked with a white star. For the myostracum (A) we find a steady increase in aragonite co-orientation strength towards the innermost myostracal surfaces. Although in the fibrous prismatic shell layer the MUD value is increased at the inner shell margin (MUD: 80 ), next to the soft tissue of the animal, within most of the fibrous prismatic shell layer MUD values are very similar (MUD: 57, 59, 64, shown in yellow in B). In the complex crossed-lamellar layer crystal co-orientation strength decreases, as indicated by a MUD value of 40 (B). The white arrow in the right-hand side image in B points to the innermost shell margin.

of the shells were obtained by cutting and polishing the sections with glass and diamond knives. The samples were then decalcified for at least an hour in a solution containing 0.25 M HEPES, $0.05 \mathrm{M}$ EDTA $(\mathrm{pH}=7.8)$, 2.5\% glutaraldehyde and $8 \%$ paraformaldehyde. This ensured simultaneous decalcification and fixation of the extracellular matrix. Decalcification was followed by washing three times with Bidest water and dehydration in an isopropanol series from $30 \%, 50 \%, 70 \%$, 

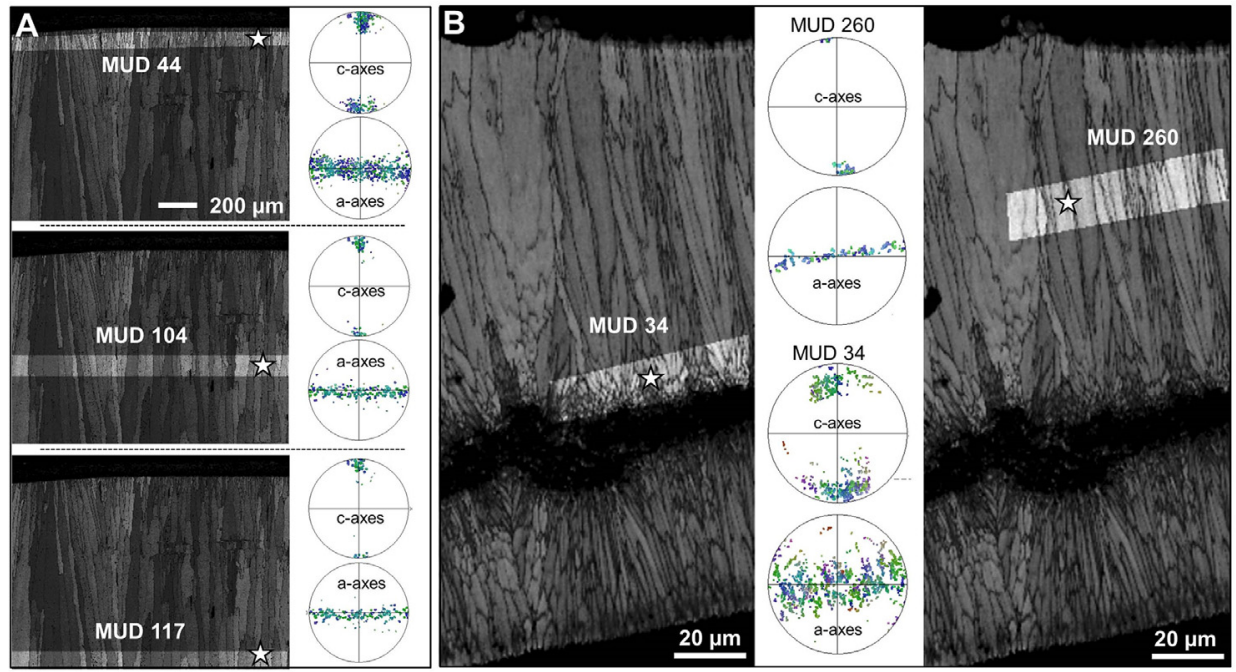

Fig. 16. Change in crystal co-orientation strength for different parts of the columnar layer of the modern brachiopod Liothyrella neozelanica (A) and in the broad chamber of the modern cephalopod Argonauta argo (B). MUD values were calculated for those regions that are highlighted in the band contrast map and are marked with a white star. For both shells crystal co-orientation strength increases progressively in the growth direction, toward inner (Liothyrella neozelanica) and outer (Argonauta argo) shell surfaces, indicating formation by competitive growth.

and $90 \%$ to $100 \%$ isopropanol. Specimens were then critical point dried, coated with $3 \mathrm{~nm}$ platinum and imaged at $4 \mathrm{kV}$ with a Hitachi S5000 FE-SEM. To expose aragonite-biopolymer matrix interfaces even sample surfaces were etched in a 0.1 M HEPES ( $\mathrm{pH}=6.5$ ) and 2.5\% glutaraldehyde solution for 90 and $120 \mathrm{~s}$. Etching was terminated by washing the samples three times in $100 \%$ isopropanol for $10 \mathrm{~s}$ each. Subsequently, samples were critical point dried, coated and imaged at $4 \mathrm{kV}$ with a Hitachi S5000 FE-SEM.

\section{Declaration of Competing Interest}

The authors declare that they have no known competing financial interests or personal relationships which have, or could be perceived to have, influenced the work reported in this article.

\section{Acknowledgements}

We thank Agostino Rizzi and Stefania Crespi for support in the SEM analysis and Curzio Malinverno for specimen preparation. Gianluca Raineri is acknowledged for providing the specimens of $G$. nummaria here analyzed. We acknowledge one anonymous reviewer and the Editor for their helpful comments on the manuscript.

GC acknowledges financial support of the 2017 Italian Ministry PRIN RX9XXY Project "Biota resilience to global change: biomineralization of planktic and benthic calcifiers in the past, present and future" to E. Erba. AGC is funded by project CGL2017-85118-P of the Spanish Ministerio de Ciencia e Innovación, the Unidad Científica de Excelencia UCE-PP2016-05 of the University of Granada, and the Research Group RNM363 of the Junta de Andalucía.

\section{Supplementary materials}

Supplementary material associated with this article can be found, in the online version, at doi:10.1016/j.dib.2020.106547. 


\section{References}

[1] G. Crippa, E. Griesshaber, A.G. Checa, E. Harper, M. Simonet Roda, W.W. Schmahl, Orientation patterns of aragonitic crossed-lamellar, fibrous prismatic and myostracal microstructures of modern Glycymeris shells, J. Struct. Biol. 212 (2020) 107653 https://doi.org/10.1016/j.jsb.2020.107653.

[2] G. Crippa, L. Angiolini, C. Bottini, E. Erba, F. Felletti, C. Frigerio, J.A.I. Hennissen, M.J. Leng, M.R. Petrizzo, I. Raffi, G. Raineri, M.H. Stephenson, Seasonality fluctuations recorded in fossil bivalves during the early Pleistocene: implications for climate change, Palaeogeogr. Palaeoclimat. Palaeoecol. 446 (2016) 234-251 https://doi.org/10.1016/j.palaeo. 2016.01.029.

[3] A.L. Johnson, E.M. Harper, A. Clarke, A.C. Featherstone, D.J. Heywood, K.E. Richardson, J.O. Spink, L.A. Thornton, Growth rate, extinction and survival amongst late Cenozoic bivalves of the North Atlantic, Hist. Biol. (2019) 1-12 https://doi.org/10.1080/08912963.2019.1663839.

[4] C. Royer, J. Thébault, L. Chauvaud, F. Olivier, Structural analysis and paleoenvironmental potential of dog cockle shells (Glycymeris glycymeris) in Brittany, northwest France, Palaeogeogr. Palaeoclimatol. Palaeoecol. 373 (2013) 123-132 https://doi.org/10.1016/j.palaeo.2012.01.033.

[5] A.M. Featherstone, P.G. Butler, B.R. Schöne, M. Peharda, J. Thébault, A 45-year sub-annual reconstruction of seawater temperature in the Bay of Brest, France, using the shell oxygen isotope composition of the bivalve Glycymeris glycymeris, Holocene 30 (2020) 3-12 https://doi.org/10.1177/0959683619865592.

[6] L.A. Casella, E. Griesshaber, X. Yin, A. Ziegler, V. Mavromatis, D. Müller, A.-C. Ritter, D. Hippler, E.M. Harper, M. Dietzel, A. Immenhauser, B.R. Schöne, L. Angiolini, W.W. Schmahl, Experimental diagenesis: insights into aragonite to calcite transformation of Arctica islandica shells by hydrothermal treatment, Biogeosciences 14 (2017) 1461-1492 https://doi. org/10.5194/bg-14-1461-2017.

[7] L.A. Casella, E. Griesshaber, M. Simonet Roda, A. Ziegler, V. Mavromatis, D. Henkel, J. Laudien, V. Häussermann, R.D. Neuser, L. Angiolini, M. Dietzel, A. Eisenhauer, U. Brand, W.W. Schmahl, Micro-and nanostructures reflect the degree of diagenetic alteration in modern and fossil brachiopod shell calcite: a multi-analytical screening approach (CL, FE-SEM, AFM, EBSD), Palaeogeogr. Palaeoclimatol. Palaeoecol. 502 (2018) 13-30 https://doi.org/10.1016/j.palaeo. 2018.03.011,

[8] R.D.K. Thomas, Functional morphology, ecology and evolutionary conservatism in the Glycymerididae (Bivalvia), Palaeontology 18 (1975) 217-254.

[9] G. Crippa, F. Ye, C. Malinverno, A. Rizzi, Which is the best method to prepare invertebrate shells for SEM analysis? Testing different techniques on recent and fossil brachiopods, Boll. Soc. Paleontol. Ital. 55 (2016) 111-125 http://dx. doi.org/10.4435/BSPI.2016.11. 